\title{
Large-scale implementation of sustainable production practices in the Priorat-Montsant region
}

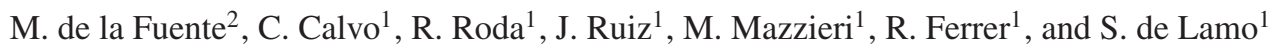 \\ ${ }^{1}$ VITEC - Centre Tecnològic del Vi, Ctra de Porrera, Km 1, 43730 Falset, Spain \\ ${ }^{2}$ PTV-Plataforma Tecnológica del Vino, C/ Musgo n², Bajo-B, 28023 Madrid, Spain
}

\begin{abstract}
The Priorat and Montsant Appellations of Origin are considered to produce some of the finest wines in the Mediterranean area of Spain. Located in the south of Catalonia (North-East Spain), they account for close to 4000 ha cultivated by more than 1300 vine growers under severe Mediterranean climatic conditions and hence threatened by global warming. In this context, sustainable practices are needed for the optimal use of natural resources in order to ensure the durability of high-quality wine production in the region. In addition, these practices allow this region to maintain high levels of biodiversity, a major characteristic of Priorat and Montsant's agricultural landscape, which represents an important touristic attraction.

The Project LIFE Priorant+Montsant, funded by the European Union, proposed the implementation of sustainable practices at a regional scale, in order to achieve remarkable reductions of resource consumption in three axes: 1) Irrigation water management, 2) vine fertilization and 3) synthetic pesticide use. Reductions are achieved by providing the necessary technical support to growers to adopt practices, developing optimized strategies and evaluating the viticulture and winery production processes.

After the two first seasons of the project, 2017 and 2018, the objectives of reduction of resources consumption have been successfully achieved. A total of 53 vineyard plots, representing the main grape varieties in the region (Grenache, Carignan, Cabernet Sauvignon and Syrah) were classified in eight sub-areas and monitored for water consumption. From pea-size to harvest (phenological stages), weekly measurements of phenology, water potential and meteorological data were collected. Irrigation recommendations were then given to growers, to avoid water potential below $-1.4 \mathrm{MPa}$. Overall, more than 50 irrigation recommendations were emitted to growers. The water consumption with the optimized irrigation strategy ranged from 10 to 63 litres per ha, the recommended dose saved 20 to $87 \%$ of the irrigation water per year, according to previous general recommendations in this region.

Regarding fertilization, soil samples were provided by growers and leave samples were taken from vineyards to assess nutrient levels and develop the corresponding recommendation of fertilization, depending on the analysis results. The analyzed soil samples from the different sub-areas were grouped by the Principal Component Analysis, in which the first and second principal components accounted for $31.6 \%$ and $11.8 \%$ of the variability and were related to soil texture and nutrient content of soils, respectively. Overall, the recommended doses of organic fertilizers saved more than $20 \%$ of the usual chemical fertilizer application in the region.

The reduction of pesticide use will be achieved through three actions related to three main pests and diseases of grapevine: optimized formulations against powdery mildew, alternative products to reduce copper use against downy mildew and, increase of surface under mating disruption strategy against grape berry moth Lobesia botrana. Before implementing these actions, no vineyards were managed under mating disruption in the Montsant area and 207 ha have been monitored in 2018 after two years. In the Priorat area, more than 200 ha have also adopted this strategy during the project. This action has saved more than 500 application doses of synthetic insecticides in those vineyards. Within the same scope, several formulations will be proved in the following years in order to assess their effectiveness against powdery and downy mildew in further specific field trials. Candidate products will be introduced in Integrated Pest Management strategies to achieve the desired pesticide reduction levels. The results will represent specific regional strategies for irrigation, fertilization and plant protection, and are extensible to most of the vineyards in Priorat and Montsant, as well as to other vitivinicultural regions which similar conditions.
\end{abstract}

Keywords: Sustainable management, Irrigation, Fertilisation, Pesticides, Priorat-Montsant.

\section{Introduction}

As the source of all life, water - and fresh water in particular - is at the centre of global concerns about the sustainable use of resources. In an agricultural framework, it accounts for an estimated 70 per cent of global water withdrawals, while competition with other sectors for water is increasing and water resources are impacted by climate change, in terms of both quantity and quality [1]. In our warm, dry climates under semiarid conditions, with low summer rainfall and high evaporative demand, all mentioned factors could appear most seriously affected, 
especially under scarce water conditions [2] or where irrigation systems have not been applied (like PrioratMontsant).

Soil, along with water, is the most important natural resource for life on Earth. However, population growth, the increasing demand for food and competing for land uses, expose it to a series of threats that increase the risks of getting it degraded or lost [3]. Reasonable fertilization and proper soil management can increase vineyard yield and sustainability. A sustainable vineyard management should cover the optimized use of fertilizers in the right dose and time, maintaining the content of organic matter, because the organic matter content is the main factor affected by soil management [4]. High development of vine root system, causing a better water and nutrients depletion and avoiding the excessive vine competition are major goals in semiarid conditions [5] related to soil management.

Reducing pesticides is one of the other targets for the sustainable vitiviniculture [6]. The use of mating disruption (MD), is widely recommended in Integrated Pest Management (IPM) strategies, because is an environmentally friendly and sustainable tool. It was shown to be effective for controlling L. botrana (Den. and Schiff.) after consecutive seasons with the application, when large areas were treated, and in years of low pest population density. The relationship between pheromonebaited trap catches and grape infestation should be evaluated in order to obtain the real efficacy [7] and could help to get an optimized control.

According to the first principle of OIV CST 518-2016 resolution [8] a sustainable and responsible use of natural resources must be implemented before establishing any vitivinicultural activity.

The main goal of this work is to settle down an integrated management for the whole Priorat region, which comprises more than 170 wineries and 1,300 wine growers registered in the two Appellations of Origin, among the all entire value chain and production systems. Results will be transferred to other vitivinicultural regions.

\section{Materials and methods}

Experiment trials were conducted (2017 and 2018) in the whole region of Priorat, including both DO Montsant and DOQ Priorat Appellations of origin, was separated into 14 sub-zones, according to geographical separation between valleys, height or other main climatic specificities.

A total 15 wineries and 3 independent vine-growers participated in the network, which means 53 vineyards being monitored covering a total of 44,72 hectares out of 100 hectares under irrigation throughout the PrioratMontsant region. Plots were relatively closely located among them and to the weather station. A complete weather station (Decagon services Inc., Pullman, U.S.A) were installed in eleven different regions (Fig. 1). Hourly data of Temperature, Relative Humidity and rainfall were collected and uploaded into the web platform CESENS $^{\circledR}$ (www . cesens . com). Participating wineries and wine growers have access to the data of all stations of each sub-zone, which represent the climatic diversity of the region, sharing with growers from the region, in order to provide reliable data to achieve a more precise interpretation of the growing season.
In some areas, humidity sensors have been installed at three depths in 3 different monitoring vineyards, which allows monitoring soil moisture (as a control) throughout the campaign and the effect of irrigation made on it.

Grape varieties were Grenache, Carignan, Cabernet Sauvignon, Merlot, Tempranillo, Syrah, Macabeo and Grenache blanc, although not every variety was represented in every sub-zone.

Plant water status was estimated measuring leaf water potential at mid-day $\left(\begin{array}{l}\psi \\ 12 h\end{array}\right)$ every two weeks, using a Scholander type pressure chamber (PMS, Portland, Oregon). Values obtained from the three samples were used to calculate a mean water potential values for a certain grape variety, which were communicated to growers instantly. When average water potential values exceeded $-1.4 \mathrm{MPa}$, a recommendation of irrigation with specific water volume to apply was emitted to the vineyard manager. The stress thresholds and recommended irrigation volume was calculated according to HidalgoTogores and Hidalgo (2011), then adjusting to variety and soil type, and targeting the specific production objective of the grower. In most of cases the recommendation targeted a moderate water stress, corresponding to a water potential between -1 and $-1.2 \mathrm{MPa}$ ). Measurements were carried out on 3 leaves per replicate and in different vines, from "berries pea-sized" to harvest, according to different phenological stages, following a weekly maturation control in the controlled vineyards. Finally, microvinifications with the grapes of the monitored vineyards were done at the end of season.

On other hand, soil analyzes will be carried out for each plot with their following nutrient analysis of leaves, in order to detect any deficiency and for monitoring the total fertilizer consumption. Foliar analyzes were done in flowering and veraison. A total of 400 soil and leaves samples have been collected (2017 and 2018), from 42 wineries and 28 vine growers of the 2 Appellations of Origin.

Finally, regarding the IPM management actions, largescale implementation of mating disruption was conducted in both regions.

D.O.Ca. Priorat increased the area using this technique in 78 ha in 2017 and 2018 together, distributed in seven municipalities (Bellmunt del Priorat, Gratallops, El Lloar, Porrera, Torroja de Priorat, La Vilella Baixa and El Molar).

D.O. Montsant implemented this technique for first time in 2017, and it has been implanted in a total area of 207 hectares since then, located between the municipalities of Falset, Garcia and El Masroig.

In all plots, 4-6 confusion traps were places depending on whether the plot is located in a trial area or control area. Controls of egg laying were done according to the three different generations for moth control. If the incidence were lower than $12 \%$, no treatment was done. More than 280 controls were done between April and October for each season.

\section{Preliminary results and discussion}

\subsection{Optimization of water management for vineyard}

In the first year (2017) of the project, water consumption in vineyards was $63 \mathrm{~mm} / \mathrm{ha}$ on average, while the 
Table 1. Vineyard plots monitored and irrigation data in 2018.

\begin{tabular}{|c|c|c|c|c|c|}
\hline Sub-zone & $\begin{array}{c}\text { Appellation } \\
\text { of origin }\end{array}$ & Municipality & $\begin{array}{c}\text { Number of } \\
\text { plots }\end{array}$ & $\begin{array}{c}\text { Irrigated } \\
\text { volume } \mathbf{( ~ m}^{-\mathbf{2}} \mathbf{)}\end{array}$ & $\begin{array}{c}\text { Reduction }^{\mathbf{1}} \\
(\mathbf{\%})\end{array}$ \\
\hline 1 & D.O. Montsant & Tivisa & 5 & 36 & 55 \\
\hline 2 & D.O. Montsant & García & 14 & 83 & -3 \\
\hline 3 & D.O. Montsant & Marça & 5 & 20 & 75 \\
\hline 4 & D.O.Q. Priorat & Bellmunt & 6 & 30 & 62 \\
\hline 5 & D.O.Q. Priorat & Porrera & 4 & 10 & 87 \\
\hline 6 & D.O.Q. Priorat & El Molar & 9 & 33 & 58 \\
\hline 7 & D.O.Q. Priorat & Gratallops & 4 & 25 & 68 \\
\hline 8 & D.O. Montsant & Cornudella & 5 & 10 & 87 \\
\hline 14 & D.O.Q. Priorat & Poboleda & 1 & 16 & 80 \\
\hline
\end{tabular}

${ }^{1}$ Reduction values are referred to a generic value of $801 \mathrm{~m}^{-2}$.

\begin{tabular}{|c|c|}
\hline Climatic zones & Data collection station \\
\hline$\underline{\text { Zone } 1}$ & Serra d'Almos $\left({ }^{*}\right)$ y Panta el Guiamets \\
\hline Zone 2 & Masroig $\left({ }^{*}\right)$ \\
\hline Zone 3 & Falset-Marça $\left({ }^{*}\right)$ y Falset \\
\hline Zone 4 & Bellmunt del Priorat $(*)$ \\
\hline Zone 5 & Porrera $(*)$ \\
\hline$\underline{\text { Zone } 6}$ & El Molar $(*)$ \\
\hline Zone 7 & Gratallops $(*)$ \\
\hline Zone 8 & Cornudella de Montsant $\left({ }^{*}\right)$ y Panta de Siurana \\
\hline$\underline{\text { Zone } 9}$ & Torroja del Priorat \\
\hline Zone 10 & Margalef \\
\hline Zone 11 & Ulldemolins \\
\hline Zone 12 & Pradell de la Teixeta $(*)$ \\
\hline Zone 13 & La Figuera $(*)$ \\
\hline Zone 14 & Poboleda $(*)$ \\
\hline \multicolumn{2}{|c|}{ * Weather stations installed by VITEC } \\
\hline \multicolumn{2}{|r|}{ D.O. Montsant } \\
\hline \multicolumn{2}{|r|}{ D.O.Q. Priorat } \\
\hline
\end{tabular}

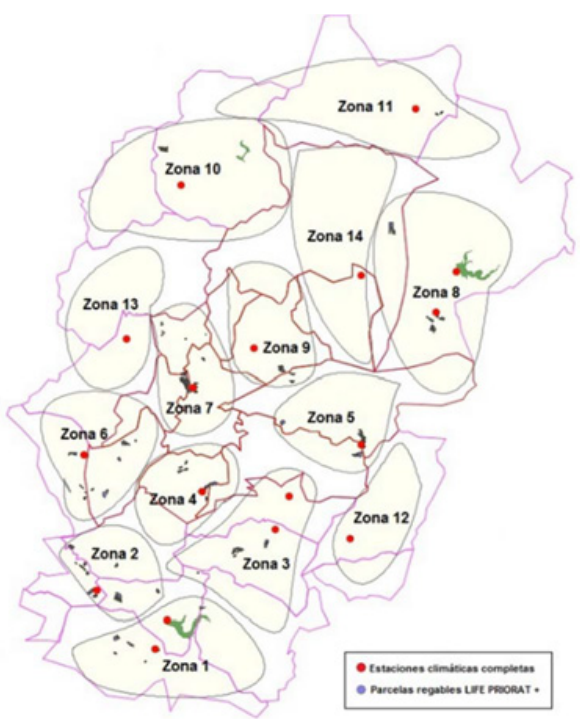

Figure 1. Distribution of all complete weather stations installed along different municipalities of the Priorat-MontSant region.

water consumption of other vineyards (where our recommendations were not followed in the region), was usually $80 \mathrm{~mm} / \mathrm{ha}$. It means more than $12 \%$ of water saved for getting the same results.

In 2018, the reduction is higher due to the climatic conditions and the increase in the number of controlled plots.

It should be noted that more than 50 irrigation recommendations and a total of 24 technical reports were provided detailing the current situation of vineyards between 2017 and 2018 for all the regions.

\subsection{Efficient use of fertilizers in the vineyard}

During these two years fertilization control was carried out in a total of 267 vineyards distributed by the Priorat region, which means a total of 254,997 hectares (120,646 hectares in D.O. Montsant and 134,351 hectares in D.O. Ca Priorat).

From the analytical results of the samples, more than 100 technical reports with recommendations of dose of fertilizer to provide were sent by VITEC, helping to save close to $20 \%$ over the average of total fertilizers amount per year usually applied in the region.
The analysed soil samples from the different subareas were grouped by the Principal Component Analysis (Fig. 2), allowed to distribute the different areas according to their texture, nutrients and organic matter in soil composition. Sub-zones 1 and 2 have silty-loam texture, whereas sub-zones $3,4,7$ y 14 have sand-loam textures. It should be remarked that first and second principal components (accounted for $31.6 \%$ and $11.8 \%$ of variability) were mainly related to soil texture and nutrient content of soils, respectively. Results shown that soils with silts and clays texture have the highest nutrient and OM content, while sandy soils are poorer compared with them.

In addition, lower magnesium content in limestone and basic soils, due to its thick silts texture.

\subsection{Efficient use of pesticides in integrated pest and disease control programs for grapevine}

Main action related to that objective was to implement the mating disruption strategy against grape berry moth Lobesia botrana, because Grapevine moth is the most important pest in this region. Before implementing it, no vineyards were managed under mating disruption in the Montsant area and only 375 in the Priorat region (Fig. 3). 

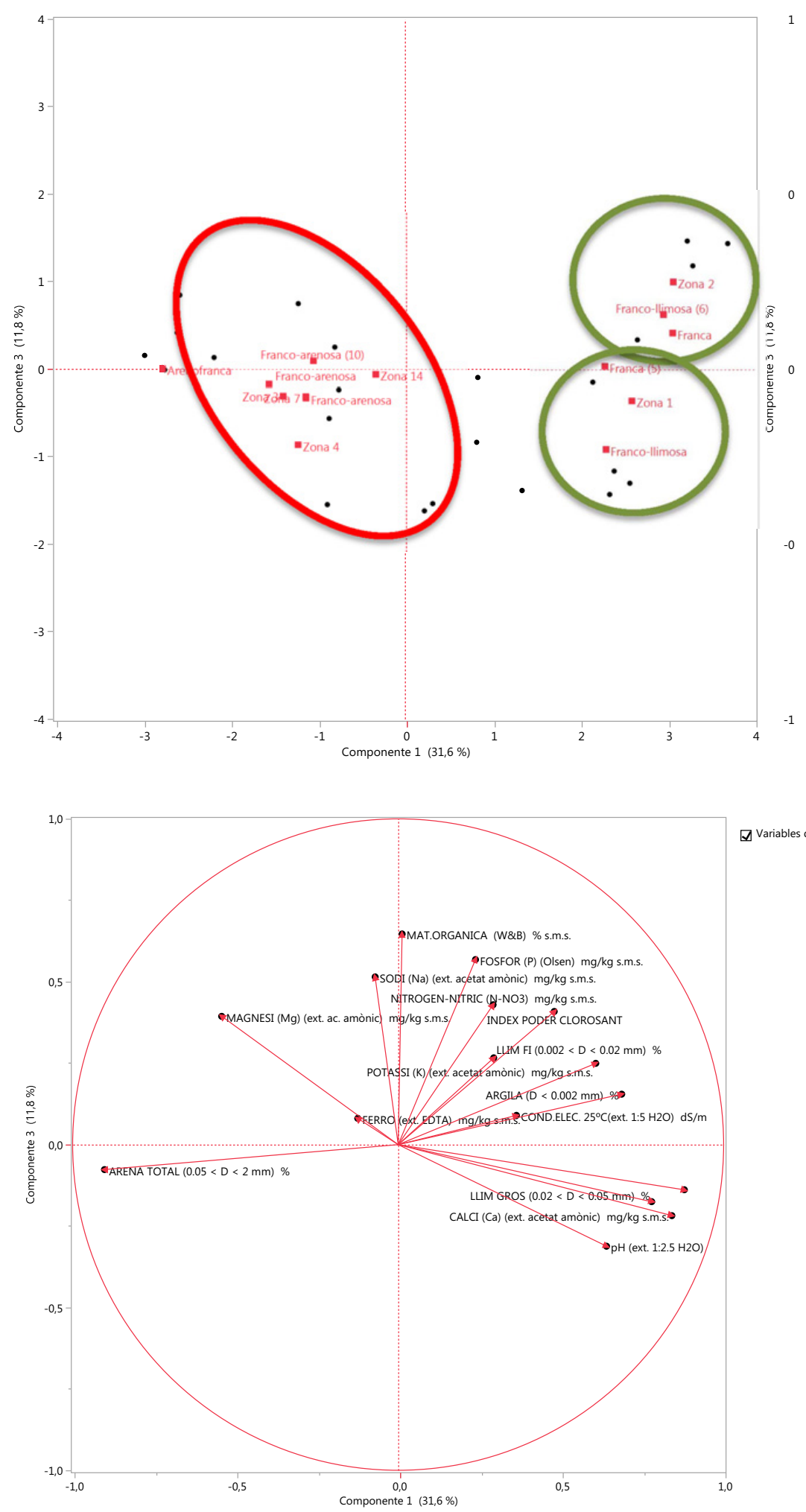

$\square$ Variables de etiqueta

Figure 2. Principal Component Analysis of soil samples in 2018from soil plots.

Regarding the D.O.Ca. Priorat, currently there are about 610 hectares under mating disruption (531 hectares in 2017), in struggle to the chemical alternative of the total of $1,153 \mathrm{ha}$ of vineyard, distributed in several locations (Bellmunt del Priorat, Gratallops, El Lloar, Porrera, Torroja de Priorat, La Vilella Baixa and El Molar). It means that in the Priorat area, 235 ha have also adopted this strategy during the project. Since common practices include one or two insecticide applications during the season, this action has saved more than 500 application doses of synthetic insecticides in those vineyards.

Results obtained in three field trials in D.O. Montsant during the last season (2018) consolidate this technique. Masroig's trial has been increased its surface under mating 


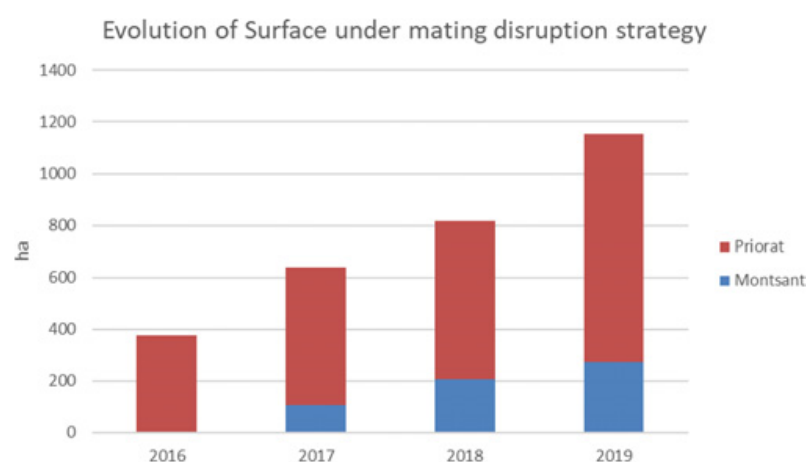

Figure 3. Evolution of surface under mating disruption in Priorat and Montsant region under the LIFE project.

disruption with 70 hectares, going from 108 the last year to 178 this one under total control of grapevine moth.

D.O. Montsant has also implemented two new trials the present year: one in Falset, (20 hectares), and other one in El Masroig (9 hectares), which means a total of 207 ha under its strategy.

In plots monitored under mating disruption strategy in both 2017 and 2018 seasons, only one insecticide treatment in 1.5 ha for the $2^{\text {nd }}$ generation has been recommended, since pest was not controlled by mating disruption.

Regarding the varietal sensitivity, some incidence has been detected close to harvest, especially in the Carignan, so next year controls could be increased during the grape cycle until harvest.

With the application of mating disruption technique, grape growers have reduced phytosanitary products in $99 \%$ of total trial surface $(817 \mathrm{ha})$. Other studies confirm similar results about total reduction of treatments with this technique $[9,10]$.

These results allow to affirm that the use of this technique (mating disruption) has worked satisfactorily in this region under its conditions [11].

In addition, grape growers that have participated in these trials, have shown a high degree of interest not only to replicate the trials, even in increasing total vineyard area treated during following years. The estimation of area under mating disruption for the 2019 season is more than 1100 ha, confirming the increase trend observed since the beginning of the project.

Furthermore, other trials will be carried out related to other main pests and diseases of grapevine in the area (Powdery and Downey mildew) in order to find optimized formulations and alternative products to reduce their applications.

Results from both type of trials can show that with mating disruption and promising candidate products (which have been thoroughly tested and proved their effectiveness), the IPM could be and interesting alternative to conventional management at a regional scale.

The authors gratefully acknowledge the LIFE program and EC for technical and financial support on the implementation of this project: "Efficiency in the use of resources for the improvement of sustainability of vine and wine sector at Priorat regionLIFE PRIORAT+MONTSANT // LIFE15 ENV/ES/000399". http://www.lifeprioratmontsant.eu/en

\section{References}

[1] FAO. WASAG, The Global Framework on Water Scarcity in Agriculture 4 (2018) http: //www. fao. org/land-water/overview/wasag/en/

[2] M. De la Fuente, R. Linares, J.R. Lissarrague, Wine \& Viticult, J. 31, 43 (2016)

[3] FAO + Italy. Partnering for Food Security and Prosperity Rome 58 (2019)

[4] R. Linares, M. De la Fuente, M.P. Junquera, J.R. Lissarrague, P. Baeza, BIO Web of Conf. 3, 01008 (2014), doi: 10.1051/bioconf/20140301008

[5] R. Linares, M. De la Fuente, M.P. Junquera, J.R. Lissarrague, P. Baeza, Australian J. Grape Wine Res. 24, 439 (2018)

[6] M. de la Fuente, J.C. Ruf. Aspects Appl. Biol. 132, 123 (2016)

[7] C. Carlos, F. Gonçalves, S. Sousa, M. Nóbrega, J. Manso, J. Salvação, J. Costa, C. Gaspar, J. Domingos, L. Silva, D. Fernandes, M.C. Val, J.C. Franco, J. Aranha, H. Thistlewood, L. Torres, IOBCWPRS Bulletin 105, 93 (2013)

[8] OIV-CST 518/2016 resolution. "OIV general principles of sustainable vitiviniculture - environmental social - economic and cultural aspects"

[9] F.O. Altindisli, F. Ozsemerci, T. Koclu, Ü. Akkan, N. Keskin, BIO Web of Conf. 7, 01029 (2016)

[10] C. Carlos, F. Gonçalves, I. Oliveira, L. Torres, Crop Protection 110, 57 (2018)

[11] F. Louis, K.J. Schirra, IOBC Wprs Bulletin 24, 75 (2001) 